\title{
Clear cell carcinoma of the pancreas: histopathologic features and a unique biomarker: hepatocyte nuclear factor-1/
}

\author{
Lisa Kim, Jie Liao, Meng Zhang, Mark Talamonti, David Bentrem, Sambasiva Rao, \\ and Guang-Yu Yang \\ Department of Pathology and Surgery, Feinberg School of Medicine, Northwestern University, \\ Chicago, IL, USA
}

\begin{abstract}
Clear cell carcinoma as a variant of ductal carcinoma of the pancreas is not well recognized. Hepatocyte nuclear factor-1 $\beta$ as a transcription factor has been identified as a specific biomarker of clear cell tumor of the female genital tract. The aim of this study was to systematically analyze clear cell carcinoma of the pancreas and its unique biomarker hepatocyte nuclear factor-1ß. A total of 84 pancreatic adenocarcinomas were analyzed pathologically and with an immunohistochemical approach with hepatocyte nuclear factor-1 $\beta$ antibody. The identified clear cell carcinomas were further studied by PAS, DPAS, and mucicarmine stains. Pathologic features and clinical follow-up were documented. Of them, $20(24 \%)$ pancreatic adenocarcinomas were identified with clear cell features, including 12 clear cell carcinomas and 8 ductal adenocarcinomas with clear cell component (defined as less than $75 \%$ of tumor with clear cells). Cytologically, the clear cell carcinomas exhibited clear cytoplasm with centrally located, atypical nuclei. PAS, DPAS, and mucicarmine stains confirmed that the clear cytoplasm was not due to accumulation of glycogen or mucin. The results of immunostaining showed that hepatocyte nuclear factor-1 $\beta$ is overexpressed in all clear cell carcinomas and in the clear cell components of eight ductal carcinomas with clear cell features. In contrast, in usual ductal adenocarcinoma, hepatocyte nuclear factor-1 $\beta$ exhibited overall weak or focally moderate staining; only eight cases were strongly positive $(15 \%)$ of which $38 \%$ were high grade and $63 \%$ were moderate grade. However, when included with the strong staining cases in mixed and clear cell carcinoma, this group regardless of morphology appeared to correlate with worse survival compared to the group with weak hepatocyte nuclear factor-1 $\beta$ staining across morphologies $(P<0.01)$. Thus, clear cell carcinoma of the pancreas is not an uncommon variant of pancreatic ductal adenocarcinoma. Hepatocyte nuclear factor-1 $\beta$ is a useful marker to identify these clear cell carcinomas, and its overexpression may aid in stratifying survival rate.
\end{abstract}

Modern Pathology (2008) 21, 1075-1083; doi:10.1038/modpathol.2008.95; published online 6 June 2008

Keywords: clear cell carcinoma; pancreatic adenocarcinoma; HNF1B

Pancreatic carcinoma is the fourth most common cause of death among cancers in both men and women $^{1}$ with 5 -year survival being quite dismal even after pancreatectomy. ${ }^{2,3}$ Both the evolution of more sophisticated imaging and better accessibility through improvements in surgical procedures have allowed more recognition of pancreatic lesions at earlier stages of detection. The current classification schemes divide pancreatic neoplasms into solid or cystic lesions and epithelial cell type: ductal, acinar, and endocrine. ${ }^{4}$ Over $90 \%$ of carcinomas diagnosed

Correspondence: Dr G-Y Yang, MD, PhD, Department of Pathology, Feinberg School of Medicine, Northwestern University, 303 East Chicago Avenue, Chicago, IL 60611, USA.

E-mail: g-yang@northwestern.edu

Received 03 January 2008; revised 27 February 2008; accepted 28 February 2008; published online 6 June 2008 in the pancreas are classified as ductal in origin. Although $80-90 \%$ are considered as conventional ductal adenocarcinoma, this category belies the great variation in morphology that has been observed and includes patterns consisting of foamy glands, large ducts, lobular carcinoma-like, and vacuolated cells.

Pancreatic adenocarcinoma with optically clear cells has been histologically noted but a systematic overview of its true existence as a definable entity is lacking in the literature outside of a few case studies. Ductal adenocarcinoma has been generally accepted to contain cells that may have abundant cytoplasm, with some descriptions of clear cell change being commonplace, often due to mucin. However, clear cell carcinoma has rarely been described. Ray et $a l,{ }^{5}$ have summarized cases in which this morphology had been described 
historically extending back to 1980. Individually these consist of seven single case reports, three of which were found on autopsy, and were overall considered to be a rare occurrence. Of those that had histochemical characterization, there was scanty, focal, or strong positivity for mucin, with one case reporting negativity for lipids by Sudan III, which contrasts descriptions from the World Health Organization as being glycogen rich. $^{6}$

Hepatocyte nuclear factor1 (HNF-1) was originally described as a novel homeodomain-containing transcription factor isolated from a human liver library and found to be essential during organogenesis of the liver, kidney, and pancreas. ${ }^{7-9}$ HNF1- $\beta$ (HNF1B), previously known as variant HNF-1, was shown to be conserved across mammalian species and actually precede expression of HNF-1 (or HNF1A) being detectable at the earliest stages of developing organs. ${ }^{10}$ HNF1A and HNF1B were mapped on different chromosomes but discovered to share homology at the homeodomain and heterodimerize with each other in the presence of DNA. ${ }^{7}$

HNF1B was found to be the most robust upregulated transcription factor in a gene expression analysis of four ovarian clear cell carcinoma cell lines when compared to non-clear cell carcinoma lines. ${ }^{11}$ It was also subsequently reported to be positive in areas of endometriosis or endometriotic epithelium in a study of ovarian clear cell carcinoma lending molecular support for the hypothesis that the concurrent endometriosis seen in ovarian clear cell carcinoma may be linked as a precursor lesion. ${ }^{12}$

The significance of clear cell carcinoma as an entity in pancreatic cancers is inadequately characterized. Our study of 84 archived cases of diagnosed pancreatic adenocarcinomas has uncovered the largest known report of a clear cell phenotype consisting of at least $75 \%$ of the tumor. Not only does this suggest that its incidence is more common than thought, these cases provide a unique opportunity to characterize the qualitative aspects of the clear cells and their clinical behavior in comparison to non-clear cell carcinoma. Furthermore, HNF1B was an attractive candidate marker in clear cell carcinoma of pancreas.

\section{Materials and methods}

\section{Pathology Specimens}

Records from the electronic database at our institution allowed for searches for all pancreatic resections extending from October 2002 to the present point of this study encompassing 45 months. These included distal pancreatectomies and pancreaticoduodenectomies. Cases of adenocarcinoma of ductal type were collected and reviewed. Carcinomas arising from intraductal papillary mucinous neoplasms and endocrine carcinomas were excluded, yielding 84 diagnosed cases of pancreatic adenocarcinoma of ductal type ranging from well to poorly differentiated. Tumor size, site, extent of invasion, and lymph node metastasis were also recorded, along with available patient follow-up or death. One to two paraffin-embedded blocks were selected from each of the available cases for immunostaining.

\section{Histochemistry and Special Stains}

Sections were cut at $5 \mu \mathrm{m}$ from formalin-fixed, paraffin-embedded tissue, deparaffinized and rehydrated. Cases with clear cell features were stained with PAS, DPAS, and mucicarmine histochemically with routine clinical methods and proper positive and negative controls.

\section{Immunohistochemistry for HNF1B}

Immunohistochemical staining was performed using the avidin-biotin-peroxidase complex method as previously described. In brief, endogenous peroxidase activity was quenched in paraffinembedded tissue sections with $1 \% \mathrm{H}_{2} \mathrm{O}_{2}$. After retrieving the antigen by pretreatment with a citrate buffer (Antigen Unmasking Solution; Vector Laboratories, Burlingame, CA, USA) in a microwave oven and blocking nonspecific protein-binding interactions with diluted normal serum, the slides were incubated with the primary mouse monoclonal antibody against HNF1B $\left(1 \mu \mathrm{g} \mathrm{ml}^{-1}-1: 100\right.$ dilution; Santa Cruz, CA, USA), followed by the appropriate biotinylated secondary antibody and the ABC complex for $45 \mathrm{~min}$ each. Diaminobenzidine was used as the chromagen. Slides were washed thoroughly between incubations with PBS. Negative controls were established by replacing the primary antibody with PBS and normal serum. Positive staining was indicated by the presence of a brown-colored precipitate.

Compared to the proper negative control and positive control, intense brown cytoplasmic and nuclear staining was scored as positive. The frequency and location of the labeled cells were evaluated and scored as '-' no staining or background staining, ' + ' mild specific staining of malignant cells, ' ++ ' moderate staining of malignant cells, and ' +++ ' the most intense staining.

\section{Statistical Methods}

$\chi^{2}$-Analysis was used for comparing results of high $v s$ low staining of HNF1B in conventional ductal carcinoma vs those with clear cell component and in the analysis of grade, lymph node metastasis, and tumor size with respect to high vs low staining with HNF1B. Statistical significance was applied if $P$-value was less than 0.05. Kaplan-Meier survival curves comparing conventional ductal carcinoma, mixed, and clear cell carcinoma cases, as well as cases with high vs low HNF1B staining were 
performed on SAS (SAS OnlineDoc ${ }^{\circledR}$ 9.1.3). P-value was obtained using the log-rank test.

\section{Results}

\section{Histopathologic Features of Clear Cell Carcinoma}

A total of 84 previously diagnosed cases of pancreatic adenocarcinoma of ductal type were reviewed. Of them, $20(24 \%)$ cases were found to have a significant degree of involvement by a clear cell component; 12 had at least $75 \%$ of infiltrating ductal carcinoma cells with clear cell features and were classified as clear cell carcinomas. The remaining eight cases had a mixture of both usual ductal and clear cell phenotypes, with clear cells consisting of less than $75 \%$ of the tumor cells. These were defined as mixed ductal carcinoma with clear cell features.

Histologically, the architecture of the clear cell component included glandular or ductal to nested structures composed predominantly of a single layer of polygonal cells with distinct cell borders and various degrees of nuclear atypia (Figure 1a); and other areas showed heaped up layers lining a still apparent duct (Figure 1a). In mixed tumors, focal clear cell features could be found within the same ductal structure that otherwise exhibited the usual eosinophilic ductal carcinoma cells (Figure 1b) found in conventional ductal adenocarcinoma (Figure 1c). The optically clear cells showed intracytoplasmic vacuoles that displaced a small, irregularly contoured, and hyperchromatic nuclei that were centrally to eccentrically placed with indistinct nucleoli (Figures 2a-d). Mitotic figures were infrequently observed. In other cases nuclei were peripherally placed and were larger, oval, with dispersed to vesicular chromatin (Figures 2e and f).

Several distinct patterns were noted among the cases of clear cell carcinoma. Similar to the conventional ductal counterpart, well-differentiated duct-like structures showed medium to small nuclei situated basally, whereas the luminal surface appeared rigid and circumferentially conscripted (Figures 2a and b). Another pattern showed cells
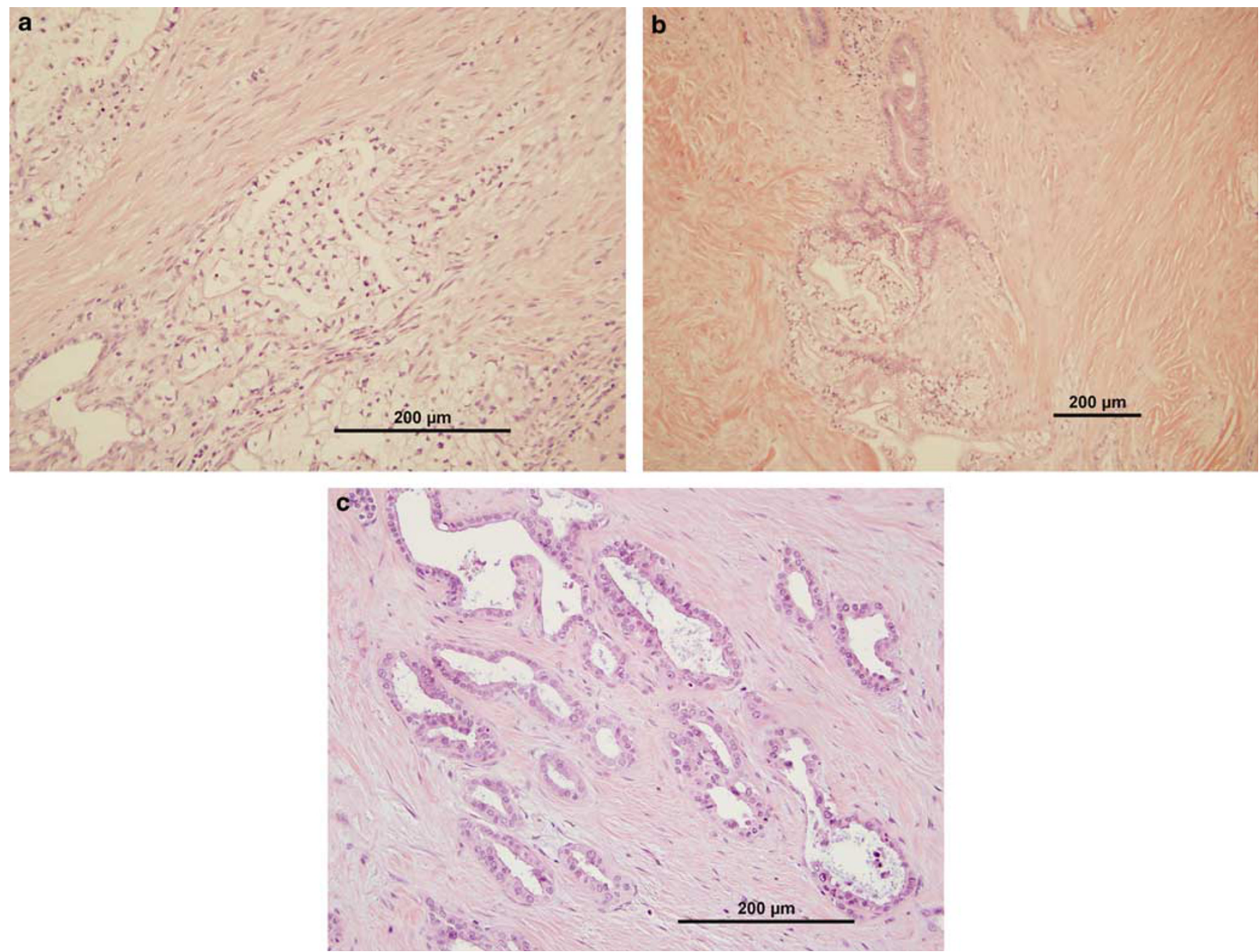

Figure 1 Representative photographs of distinct types of pancreatic ductal carcinoma: (a) Clear cell carcinoma in which clear cells consist of more than $75 \%$ of tumor. (b) Carcinoma with both usual ductal and clear cell component, consisting of less than $75 \%$ of overall tumor. (c) Conventional or usual ductal adenocarcinoma, at diagnosis, well to moderately differentiated. 

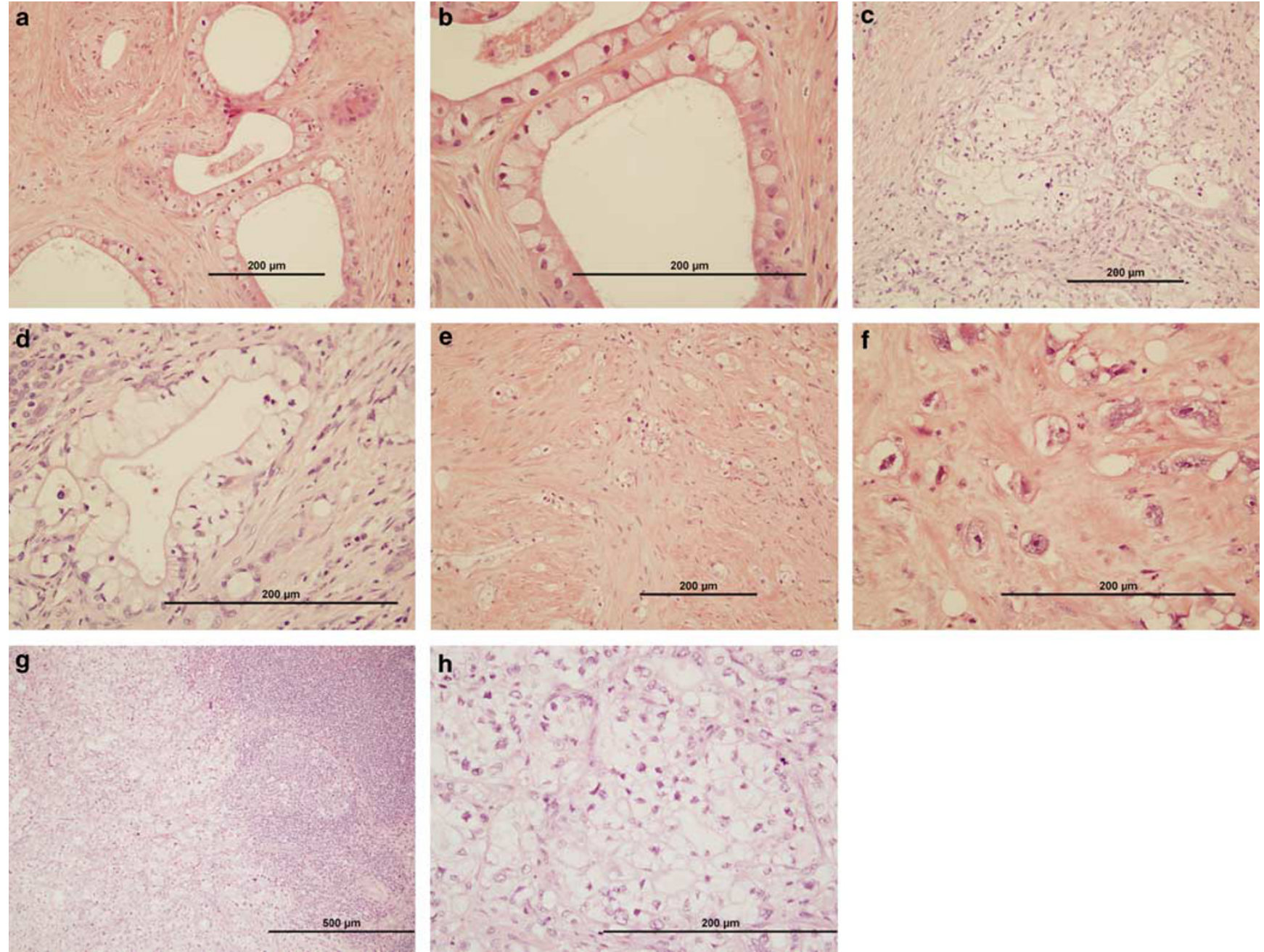

Figure 2 Representative photographs demonstrating spectrum of differentiation of clear cell carcinoma: (a, b) well-differentiated; (c, d) moderately differentiated tumor shows transition to less rigid duct-like features with glomeruloid or piled up growth into the lumen. Nuclei appear to lose basal polarity and become centrally placed. (e, f) Poorly differentiated tumor with nests of tumor cells dispersed in stroma and increased nuclear atypia; (g, h) clear cell carcinoma metastatic to lymph node. (low magnification in a, $\mathbf{c}, \mathbf{e}$, and $\mathbf{g}$ and high magnification in $\mathbf{b}, \mathbf{d}, \mathbf{f}$, and $\mathbf{h}$ ).

becoming dispersed in nests of $5-6$ cells without lumen or singly dispersed in the stroma. Nuclei were more centrally placed and showed increased atypia (Figures 2e and f). There were mixtures between these two patterns that appeared to be in various states of transition from the better differentiated to the dispersed and poorly differentiated cases (Figures 2c and d). Furthermore, metastatic clear cell carcinoma in the lymph nodes maintained a poorly differentiated pattern (Figures $2 \mathrm{~g}$ and $\mathrm{h}$ ).

To elucidate the nature of the clear cells, PAS with and without diastase treatment, and mucicarmine stains were performed. The contents of the vacuoles in the cytoplasm of clear cells were devoid of glycogen (PAS and DPAS stains in Figures 3a and b) and mucin of neutral, acid-simple nonsulfated, or acid-complex sulfated types (Figure 3c). However, apical surface-stained glycoproteins by PAS and DPAS were observed.

\section{Clinical Characteristics of Clear Cell Carcinoma}

It was of interest to compare the clinical characteristics of the clear cell phenotype against conventional ductal adenocarcinoma (Table 1). The 64 cases of conventional ductal carcinoma did not appear to differ much compared to the 20 cases showing clear cell features with respect to average age (66 vs 68 years, respectively), or sex (50 vs 45\% men, respectively). The size of tumor involvement ranged from 1 to $9 \mathrm{~cm}$ in greatest dimension in conventional ductal and $0.9-5.5 \mathrm{~cm}$ in clear cell cases. Chemoradiation therapy preceded resection in five cases of the conventional ductal group, two in the clear cell group. Lymph node metastases were present in 36 cases of conventional $(56 \%)$ vs 10 $(50 \%)$ cases with clear cell features. Neither group had any tumors of low grade; the majority of tumors were of moderate grade (60\% conventional, $65 \%$ clear cell) and the remainder were high grade $(36 \%$ 

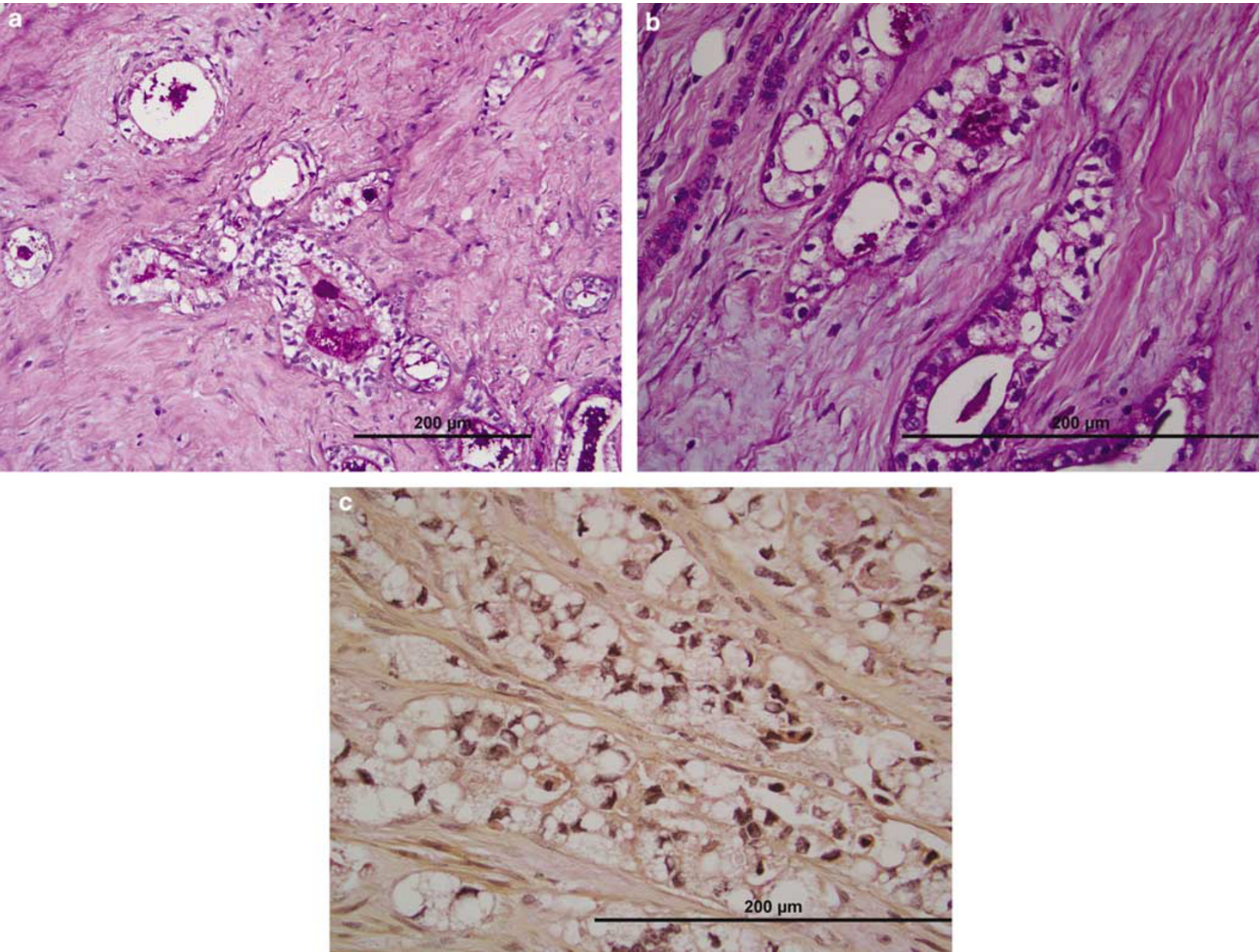

Figure 3 Histochemical staining of clear cell carcinoma: the cytoplasm of clear cells do not stain with PAS (a), PAS with diastase digestion (b), or with mucicarmine (c).

conventional, 35\% clear cell). By the revised TNM staging guidelines, $55 \%$ of conventional tumors were stage IIB, $20 \%$ stage IB, $12.5 \%$ stage IIA, $9 \%$ stage IA, and $3 \%$ stage IV; $55 \%$ of clear cell cases were stage IIB, $25 \%$ stage IIA, $10 \%$ stage IB, and one case each for stage IA and III.

Survival data was collected with the end point of the study 14 months after the most recently resected case. Overall, $56 \%$ of patients with conventional ductal carcinoma died, whereas $65 \%$ of patients with clear cell morphology died (Table 1). Comparing survival curves of conventional, mixed, and clear cell carcinoma cases was not statistically significantly $(P$-value $<0.69)$ (Figure 4$)$.

\section{Expression Pattern of HNF1B Immunohistochemistry in Clear Cell Carcinomas}

To determine if HNF1B could be a unique biomarker of clear cell carcinoma in pancreas, immunostaining was performed and was differentially expressed in both the conventional and clear cell cases. There was strong positivity in the neoplastic clear cells (Figures 5a-d). All cases of clear cell carcinoma showed strong staining $(100 \%, 2+$ and $3+)$ (Figures $5 \mathrm{~b}$ and $\mathrm{d}$ ), whereas in the 54 cases of conventional ductal adenocarcinoma, the majority, $61 \%$, showed weak ( $1+$ or no) HNF1B positivity (Figure 5f), 24\% showed $2+$ positivity. Only eight cases $(15 \%)$ were recorded as $3+$ which consisted of three (38\%) high-grade and five $(63 \%)$ moderate-grade carcinomas (Table 2). $\chi^{2}$-Analysis showed strong vs weak HNF1B staining in conventional ductal carcinoma $v s$ mixed and clear cell carcinoma to be statistically significant $(P<0.004)$. Grade, lymph node metastasis, and tumor stage were not statistically significant between the high vs low staining groups with HNF1B. Survival analysis stratified by degree of HNF1B staining without regard to morphologic subtype showed decreased survival with high HNF1B staining to be statistically significant $(P<0.01)$ (Figure 6). 
Table 1 Clinical characteristics of conventional ductal carcinoma vs carcinoma with clear cells

\begin{tabular}{|c|c|c|c|c|}
\hline & \multicolumn{2}{|c|}{ Conventional } & \multicolumn{2}{|c|}{ Mixed and clear cell carcinoma } \\
\hline & No. of cases & Total (\%) & No. of cases & Total (\%) \\
\hline Total & 64 & $76.2(64 / 84)$ & 20 & $23.8(20 / 84)$ \\
\hline \multicolumn{5}{|l|}{ Age } \\
\hline Youngest & 50 & & 52 & \\
\hline Oldest & 88 & & 85 & \\
\hline Average & 66.4 & & 68 & \\
\hline \multicolumn{5}{|l|}{ Sex } \\
\hline Men & 32 & $50(32 / 64)$ & 9 & $45(9 / 20)$ \\
\hline Women & 32 & $50(32 / 64)$ & 11 & $55(11 / 20)$ \\
\hline \multicolumn{5}{|l|}{ Tumor stage } \\
\hline T1 & 11 & $17(11 / 64)$ & 2 & $10(2 / 20)$ \\
\hline $\mathrm{T} 2$ & 26 & $41(26 / 64)$ & 7 & $35(7 / 20)$ \\
\hline T3 & 27 & $42(27 / 64)$ & 10 & $50(10 / 20)$ \\
\hline $\mathrm{T} 4$ & & & 1 & $5(1 / 20)$ \\
\hline Positive LN & 36 & $56(36 / 64)$ & 10 & $50(10 / 20)$ \\
\hline \multicolumn{5}{|l|}{ Grade } \\
\hline Low & 0 & 0 & 0 & 0 \\
\hline Moderate & 38 & $59(38 / 64)$ & 13 & $65(13 / 20)$ \\
\hline High & 23 & $36(23 / 64)$ & 7 & $35(7 / 20)$ \\
\hline \multicolumn{5}{|l|}{ Stage } \\
\hline IA & 6 & $9(6 / 64)$ & 1 & $5(1 / 20)$ \\
\hline IB & 13 & $20(13 / 64)$ & 2 & $10(2 / 20)$ \\
\hline IIA & 8 & $13(8 / 64)$ & 5 & $25(5 / 20)$ \\
\hline IIB & 35 & $55(35 / 64)$ & 11 & $55(11 / 20)$ \\
\hline III & 0 & 0 & 1 & $5(1 / 20)$ \\
\hline IV & 2 & $3(2 / 64)$ & 0 & 0 \\
\hline
\end{tabular}

LN, lymph node.

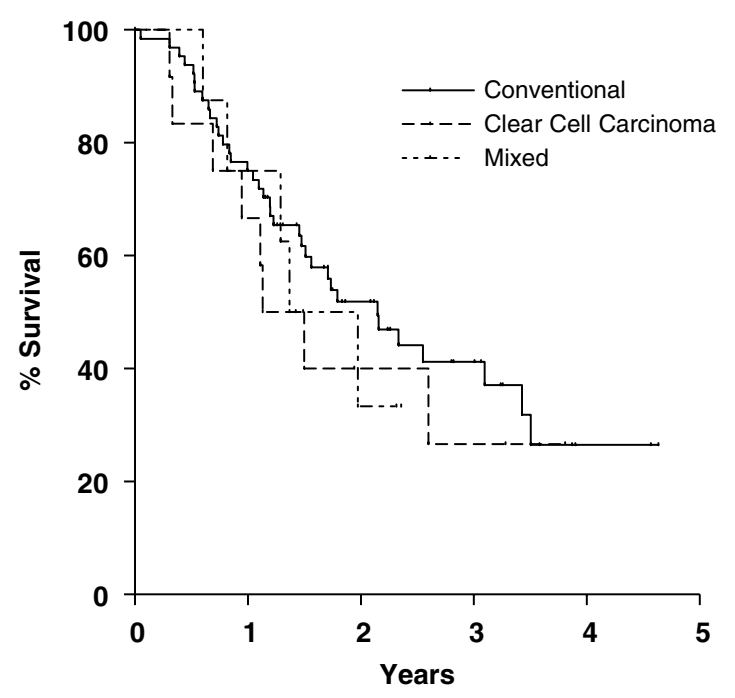

Figure 4 Kaplan-Meier survival curves comparing conventional ductal, mixed, and clear cell carcinoma were not significantly different $(P<0.69)$.

\section{Discussion}

To date, this is the largest known collection of a clear cell variant of pancreatic adenocarcinoma of ductal origin. Although clear cell carcinomas are recognized entities in other organs, prior reports in the pancreas have all stated its rarity. In addition most scattered occurrences in the literature have been described as single case reports, several of which were classified upon autopsy. ${ }^{5,13,14}$ However, in a discussion of histologic types of ductal adenocarcinomas, clear cells have been recognized as a common but 'focal finding' ${ }^{4}$ with the production of mucin. No report has adequately characterized clear cell carcinoma or provided prognosis data.

Other possibilities in the differential diagnosis of clear cell carcinomas of pancreatic primary have been reported as variants of solid pseudopapillary tumors and endocrine tumors. ${ }^{15-17}$ In addition, metastatic renal cell carcinoma, and perivascular epithelioid cell tumor can also be considered. These entities are all often eliminated by negative neuroendocrine markers, vimentin, CD10, or HMB45.

At our institution pancreatic resections for benign and malignant neoplasms are not rare procedures. In addition, we found adenocarcinoma of ductal origin with clear cell features not rare occurrences at all. In total, 20 cases were identified with a significant clear cell component and in 12 cases, the clear cells made up greater than $75 \%$ of the invasive tumor. Although a battery of immunohistochemistry was 

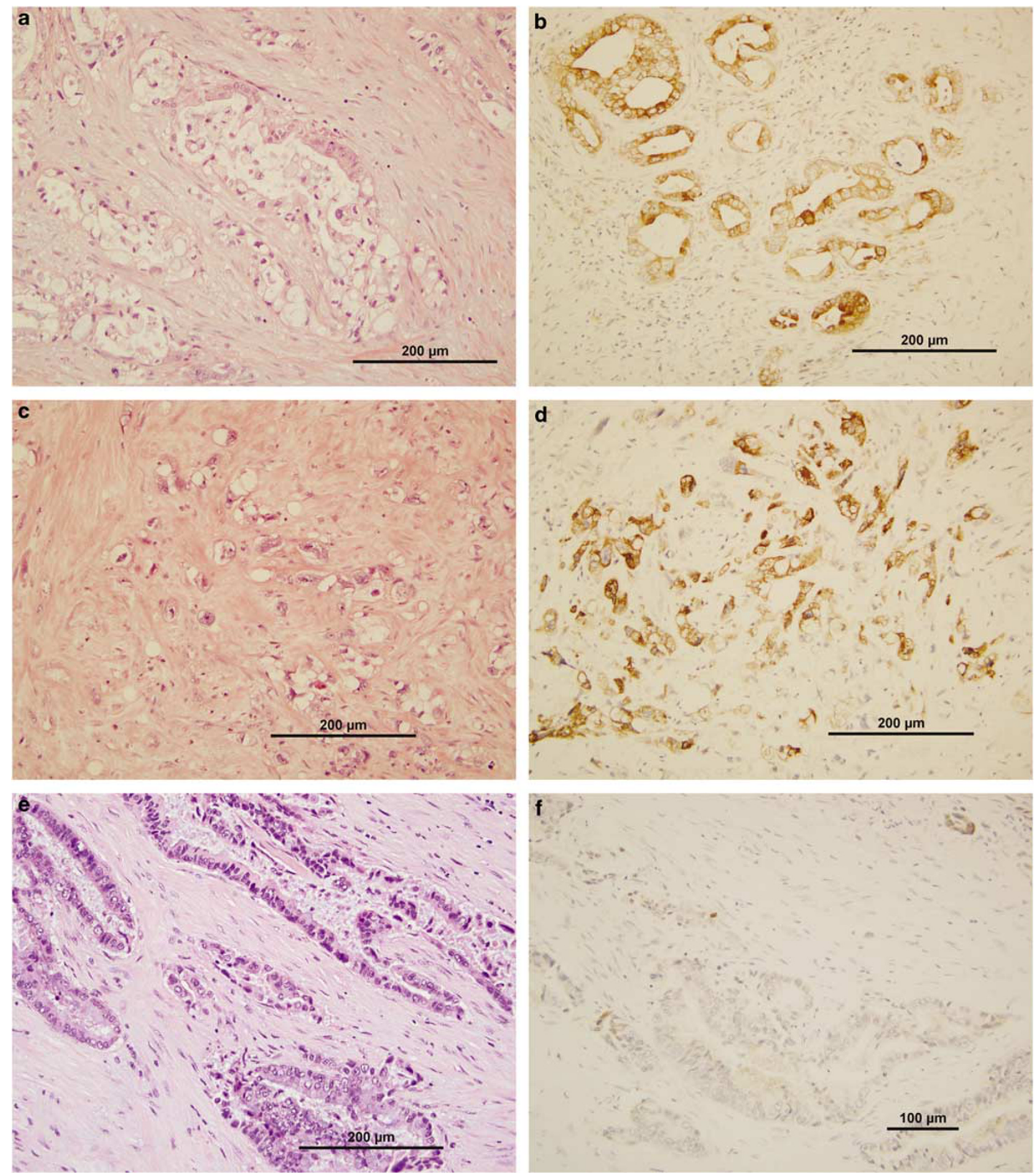

Figure 5 HNF1B immunohistochemistry in moderately differentiated, (b) poorly differentiated, (d) and usual ductal adenocarcinoma, (f). (a, c, and $\mathbf{e}$ are corresponding H\&E stained slides for $\mathbf{b}$, $\mathbf{d}$, and $\mathbf{f}$, respectively).

not performed to ascertain the ductal origin of these carcinomas, there was obvious morphologic evidence to eliminate the other entities. In the literature the characteristics of the clear cells themselves have conflicted, varying from case to case in regard to cytoplasmic content, amount of desmoplastic stro- 
Table 2 HNF1B immunostaining in conventional ductal carcinoma vs ductal carcinoma with clear cell component ${ }^{\mathrm{a}}$

\begin{tabular}{|c|c|c|c|c|c|c|}
\hline \multirow[t]{2}{*}{ HNF1B score } & \multicolumn{2}{|c|}{ Conventional ductal carcinoma } & \multicolumn{2}{|c|}{ Mixed and clear cell carcinoma } & \multicolumn{2}{|c|}{ Clear cell carcinoma } \\
\hline & No. of cases & Total $(\%)$ & No. of cases & Total (\%) & No. of cases & Total $(\%)$ \\
\hline 3 & 8 & 15 & 10 & 56 & 9 & 90 \\
\hline 2 & 13 & 24 & 4 & 22 & 1 & 10 \\
\hline 1 & 22 & 41 & 4 & 22 & & \\
\hline 0 & 11 & 20 & 0 & 0 & & \\
\hline Total no. of cases & 54 & & 18 & & 10 & \\
\hline
\end{tabular}

${ }^{\mathrm{a}}$ All cases of clear cell carcinoma showed strong $(2+, 3+)$ staining with HNF1B antibody. $\chi^{2}$-Test shows strong vs weak HNF1B staining in conventional ductal carcinoma vs mixed and clear cell carcinoma to be statistically significant $(P<0.004)$.

HNF1B, hepatocyte nuclear factor-1 $\beta$.

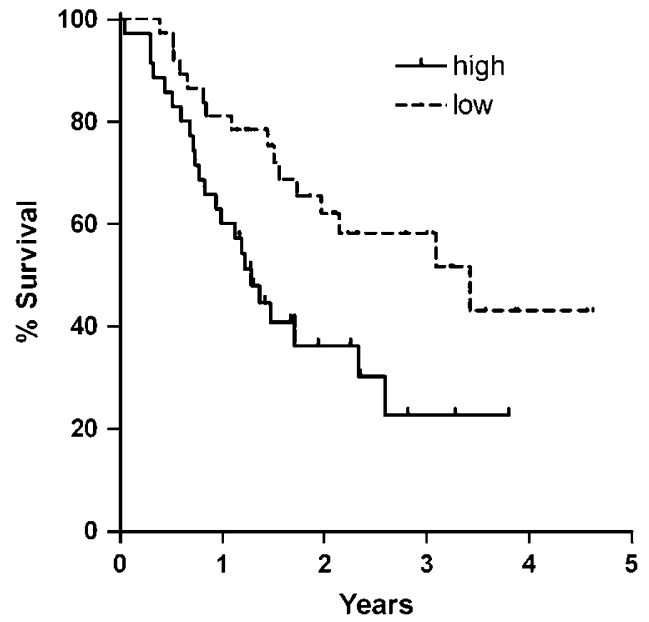

Figure 6 Kaplan-Meier survival curve comparing degree of HNF1B expression. High expression of HNF1B showing worse survival was statistically significant using log-rank test $(P<0.01)$.

or exhibit k-Ras mutations, yet all immunohistochemistry performed aligned the tumor with a ductal adenocarcinoma.

A single case series in the literature described a foamy gland pattern of ductal adenocarcinoma that bears some similarity to our clear cell phenotype. ${ }^{19}$ Like our series, these variant cells were not uncommonly seen in some combination with usual ductal carcinoma and a 'pure' form was characterized by the predominance of the foamy neoplastic cells. The cytoplasm of the foamy cells were also negative for mucin and glycogen, however, an apical zone was described strongly positive for Alcian blue, HID-AB, and mucicarmine. This apical zone ultrastructurally corresponded to smaller, more electron-dense vesicles than those seen in the remainder of the cytoplasm. In other nonductal clear cell tumors of the pancreas, electron-lucent vacuoles have also been demonstrated ultrastructurally. These are clear cells associated with endocrine origin, appear to be lipid vacuoles, and have been associated with von Hippel-Lindau disease. ${ }^{15,20}$ Whether the foamy gland pattern or clear cell pattern of nonductal pancreatic neoplasms are governed by the same process to cause vesicle or vacuole formation is unclear.

Not only have we demonstrated here that a clear cell variant of ductal adenocarcinoma exists with fair frequency, we have also shown that these cells are marked by overexpression of HNF1B compared to its conventional ductal counterpart with statistical significance. HNF1B was found to be significantly upregulated in ovarian clear cell carcinomas compared to non-clear cell phenotypes, ${ }^{11}$ but has not been studied in the pancreas. Mutations of this homeodomain-containing transcription factor also known as TCF2 (transcription factor 2) have been associated with several syndromes affecting the kidneys, ovary, and pancreas including type 5 maturity-onset diabetes of the young. Various mutations in the DNA-binding domain of HNF1B were identified in probands from eight different families who had a spectrum of structural renal abnormalities, diabetes, and in five of six patients who had undergone CT imaging, there was also diffuse atrophy of the exocrine pancreas. ${ }^{21}$ Germ-line HNF1B mutations were found in two patients with chromophobe renal cell carcinoma with one patient incidentally discovered to have absence of the body and tail of the pancreas. ${ }^{22}$

As ubiquitous as HNF1B expression may be for proper development of the pancreas and kidney its upregulation may be involved in the pathway to neoplastic conditions. However, both in the ovary and pancreas it appears to be specific to a cell type that is optically clear on routine $\mathrm{H} \& \mathrm{E}$ staining. Whatever the mechanism that is responsible for the clear cell variant, HNF1B regulation may be significant. The few cases of strong staining in our conventional ductal carcinoma cases may be postulated to carry mutations of HNF1B that have not yet manifested morphologically in clear cells. However, when included with the strong staining cases in mixed and clear cell carcinoma, this group regardless of morphology appeared to correlate with worse survival compared to the group with weak staining across morphologies. More studies are necessary to determine the significance of this staining pattern with respect to tumor biology and malignant behavior. 


\section{References}

1 Jemal A, Siegel R, Ward E, et al. Cancer statistics, 2007. CA Cancer J Clin 2007;57:43-66.

2 Brennan MF, Kattan MW, Klimstra D, et al. Prognostic nomogram for patients undergoing resection for adenocarcinoma of the pancreas. Ann Surg 2004;240: 293-298.

3 Conlon KC, Klimstra DS, Brennan MF. Long-term survival after curative resection for pancreatic ductal adenocarcinoma. Clinicopathologic analysis of 5-year survivors. Ann Surg 1996;223:273-279.

4 Hruban RH, Pitman MB, Klimstra DS, American Registry of Pathology, Armed Forces Institute of Pathology (US). Tumors of the Pancreas. American Registry of Pathology in collaboration with the Armed Forces Institute of Pathology: Washington, DC, 2007. xviii, pp 422.

5 Ray S, Lu Z, Rajendiran S. Clear cell ductal adenocarcinoma of pancreas: a case report and review of the literature. Arch Pathol Lab Med 2004;128:693-696.

6 Aaltonen LA, Hamilton SR, World Health Organization, International Agency for Research on Cancer. Pathology and Genetics of Tumours of the Digestive System. IARC Press: Oxford University Press (distributor): Lyon, Oxford, 2000. pp 314.

7 Bach I, Mattei MG, Cereghini S, et al. Two members of an HNF1 homeoprotein family are expressed in human liver. Nucleic Acids Res 1991;19:3553-3559.

8 Cereghini S, Ott MO, Power S, et al. Expression patterns of vHNF1 and HNF1 homeoproteins in early postimplantation embryos suggest distinct and sequential developmental roles. Development 1992;116: 783-797.

9 Cereghini S, Raymondjean M, Carranca AG, et al. Factors involved in control of tissue-specific expression of albumin gene. Cell 1987;50:627-638.

10 Cereghini S. Liver-enriched transcription factors and hepatocyte differentiation. FASEB J 1996;10:267-282.

11 Tsuchiya A, Sakamoto M, Yasuda J, et al. Expression profiling in ovarian clear cell carcinoma: identification of hepatocyte nuclear factor-1 beta as a molecular marker and a possible molecular target for therapy of ovarian clear cell carcinoma. Am J Pathol 2003;163: 2503-2512.

12 Kato N, Sasou S, Motoyama T. Expression of hepatocyte nuclear factor-1beta (HNF1beta) in clear cell tumors and endometriosis of the ovary. Mod Pathol 2006;19:83-89.

13 Kanai N, Nagaki S, Tanaka T. Clear cell carcinoma of the pancreas. Acta Pathol Jpn 1987;37:1521-1526.

14 Luttges J, Vogel I, Menke M, et al. Clear cell carcinoma of the pancreas: an adenocarcinoma with ductal phenotype. Histopathology 1998;32:444-448.

15 Hoang MP, Hruban RH, Albores-Saavedra J. Clear cell endocrine pancreatic tumor mimicking renal cell carcinoma: a distinctive neoplasm of von HippelLindau disease. Am J Surg Pathol 2001;25:602-609.

16 Albores-Saavedra J, Simpson KW, Bilello SJ. The clear cell variant of solid pseudopapillary tumor of the pancreas: a previously unrecognized pancreatic neoplasm. Am J Surg Pathol 2006;30:1237-1242.

17 Ordonez NG, Silva EG. Islet cell tumour with vacuolated lipid-rich cytoplasm: a new histological variant of islet cell tumour. Histopathology 1997;31:157-160.

18 Sasaki A, Ishio T, Bandoh T, et al. Clear cell carcinoma of the pancreas: an adenocarcinoma with unusual phenotype of duct cell origin. J Hepatobiliary Pancreat Surg 2004;11:140-144.

19 Adsay V, Logani S, Sarkar F, et al. Foamy gland pattern of pancreatic ductal adenocarcinoma: a deceptively benign-appearing variant. Am J Surg Pathol 2000; 24:493-504.

20 Singh R, Basturk O, Klimstra DS, et al. Lipid-rich variant of pancreatic endocrine neoplasms. Am J Surg Pathol 2006;30:194-200.

21 Bellanne-Chantelot C, Chauveau D, Gautier JF, et al. Clinical spectrum associated with hepatocyte nuclear factor-1beta mutations. Ann Intern Med 2004;140: 510-517.

22 Rebouissou S, Vasiliu V, Thomas C, et al. Germline hepatocyte nuclear factor 1alpha and 1beta mutations in renal cell carcinomas. Hum Mol Genet 2005;14: 603-614. 